\title{
Building Collapse Study Using Near Surface Geophysical Method in Parts of Akwa Ibom State, Nigeria
}

\author{
Nsidibe Akata ${ }^{1}$ Wilson Osung ${ }^{2}$ \\ 1.Diviem Nigeria Ltd, Victoria Island, Lagos State, Nigeria \\ 2.Petroleum Training Institute (PTI), Effurun, Delta State, Nigeria
}

\begin{abstract}
Adequate knowledge of the geology and the structures of the subsurface would assist engineers in the best way to carry out constructions to avoid building collapse. In this study, near surface seismic refraction method was used to determine the geotechnical parameters of the subsurface. The refracted travel times of all recorded traces were picked and analyzed using seisImager packages of pickwin and IXrefract software. The seismic tomography section revealed two geologic layers in the study area. That is, layers 1 and 2 . The P-wave velocity of the first layer ranged from 500.4 to $901.2 \mathrm{~m} / \mathrm{s}$ while in the second layer, the velocity was between 720 and $1010.3 \mathrm{~m} / \mathrm{s}$. The S-wave velocity of the first layer ranged from 400.0 and $720.5 \mathrm{~m} / \mathrm{s}, 510.0$ and $901.2 \mathrm{~m} / \mathrm{s}$ in the second layer respectively. In layer 1: Poisson ratio ranged from 1.49 to 1.99, Young's modulus ranged from between -425.1 to $-2021.1 \mathrm{KN} / \mathrm{m}^{2}$, Lames constant ranged from 245.8 to $313.8 \mathrm{KN} / \mathrm{m}^{2}$, Shear modulus ranged from -613.1 to $2518.7 \mathrm{KN} / \mathrm{m}^{2}$, Ultimate capacity ranged from 680.0 to $1282.7 \mathrm{~N} / \mathrm{m}^{2}$, Allowable capacity ranged from 170.0 to $320.7 \mathrm{~N} / \mathrm{m}^{2}$, Material index ranged from 0.97 to 2.97 , Concentration index -1.03 to 132.8 , Density gradient ranged from -3.98 to -4.99 and Stress ratio ranged from 0.007 to -0.16 . In layer 2: Poisson ratio ranged from 1.36 to 2.94, Young's modulus ranged from between 240.5 to $1597.7 \mathrm{KN} / \mathrm{m}^{2}$, Lames constant ranged from -108.5 to 965.8 $\mathrm{KN} / \mathrm{m}^{2}$, Shear modulus ranged from 432.9 to $3153.1 \mathrm{KN} / \mathrm{m}^{2}$, Ultimate capacity ranged from 102 to $180.24 \mathrm{~N} / \mathrm{m}^{2}$, Allowable capacity ranged from 255.0 to $450.6 \mathrm{~N} / \mathrm{m}^{2}$, Material index ranged from 0.43 to 6.97 , Concentration index 0.09 to 7.99 , Density gradient ranged from -3.71 to -6.89 and Stress ratio ranged from -1.51 to -3.80 . The geologic formation in the second layer was found to be more competent than the first layer with high allowable capacity and low ultimate failure potential.
\end{abstract}

Keywords- Building collapse, Near surface, Geophysical, Young Modulus, Shear Modulus

DOI: $10.7176 / \mathrm{JNSR} / 10-4-03$

Publication date: February $29^{\text {th }} 2020$

\section{Introduction}

The incidence of building collapse in Nigeria has become major concern of individuals as it affects the quality of life and properties. It therefore, poses a serious challenge to subsurface-geophysicists, engineers, building consultants, governments, landlords and other land users. Typical example of collapsed building is the Reigners Bible Church Uyo, Akwa Ibom State that claim much lives and properties worth billions of naira as shown in "Figs. 4 to 7". This collapse has been attributed to a number of factors such as inadequate information about the soil subsurface, elastic, bearing capacity, poor engineering and foundation design of the materials "(Fatoba et al. 2010 \& George et al. 2010, Zhang and Toksoz, 1998)". In order to prevent loss of lives and cost suffered in the cases of building collapse, it is important to understand the subsurface characteristics and the geologic condition of the soil before there are recommended for construction purposes "( Coker et al. 2013 and Oyedele et al. 2011)". A foundation is the supporting base of the structure which forms the interface across which the loads are transmitted to the underlying rock. Thus, if the structural loads are transmitted to the near surface soil a near surface foundation is formed which includes; mat foundation and spread footing "(George et al. 2010)". However, in order to assess the subsurface, seismic refraction method was employed in this study to assess the vulnerability of the near surface and correlate the result with lithology of the area in order to determine the depth to the most competent layer in the area of study "(Aka and Umoh, 2013)". The seismic refraction technique is highly useful in many applications such as engineering, environmental, groundwater, hydrocarbon and mineral exploration to characterize the subsurface structure (Harry et al, 2018) and geological condition "(Dobrin 1976 \& Keller et al. 1981". This method divides the subsurface structure into different layers and it gives information on the engineering parameters of each layer and their thicknesses "(Aka et al. 2018)".

Seismic refraction method operates on the principle that the speed of propagation of seismic energy varies with the medium of propagation. The study of seismic refraction induced seismic waves into the earth as primary (P) and secondary (S) waves. The waves generated by the energy sources and detected by arrays of geophone and seismograph recorder in the layered profiles for near surface profile data. The travel times of refracted $\mathrm{P}$ and $\mathrm{S}$ waves are measured and velocities are calculated along with elastic, bearing capacity and engineering properties. The alarming rate of building collapse has necessitated the knowledge about the structure of the subsurface especially in area where lands are recovered from water bodies for the purpose of construction. These locations are known to contain geologic formations which are mechanically unstable for siting an engineering 
structure. Therefore, adequate approach of investigation must be employed in order to study this type of terrain giving consideration to the high number of casualties that would be recorded and the worth of resources that would waste, if the result obtained does not properly represent the condition of the subsurface. Building collapse is said to have taken place when there are unacceptable differences between expected and observed performance of any structure. Building collapse ranges from settlement, upthrust and total collapse as shown in "Figs. 5 to 7" respectively. However, some earth materials, due to their nature, cannot support solid and rigid structure such as clay while sands and fresh basement rock provide firm support for solid foundation. On the other hand, foundation of any structure is meant to transfer the load of the structure to the ground without causing the ground to respond with uneven and excessive movement.

\subsection{Geology of the area}

Uyo is found in South-South region of Nigeria and is the capital of Akwa Ibom State. It is located within Latitudes $4^{0} 57^{1} \mathrm{~N}$ to $5^{0} 30^{1} \mathrm{~N}$ and Longitudes $7^{0} 56^{1} \mathrm{E}$ to $7^{0} 60^{1} \mathrm{E}$ with an elevation of $196 \mathrm{~m}$ above the sea level. It is bordered on the south by Nsit Atai, Nsit Ibom and Etinan Local Government Area, on the west by Abak Local Government Area, on the North by Ikono and Itu Local Government Areas of Akwa Ibom State with a total area of $255.9 \mathrm{~km}^{2}$ as shown in "Fig 1". It is underlain by sedimentary formation of late tertiary and Holocene ages within the equatorial rain forest belt, which is a tropical zone and home to vegetation of green foliage of trees, shrubs and oil palm trees. It is a tourism attraction center which includes: Ibom plaza park, Le meridian hotel and Golf resort. Also, home of the Ibom E-Library, a world-class information and research Centre. The Uyo Local government Area has three distinct vegetation zones and two seasons: saline water swamp forest, fresh water swamp forest and rain forest; wet and dry seasons. The major occupations of the people in the area are trading, crafting making, transportation businesses and education

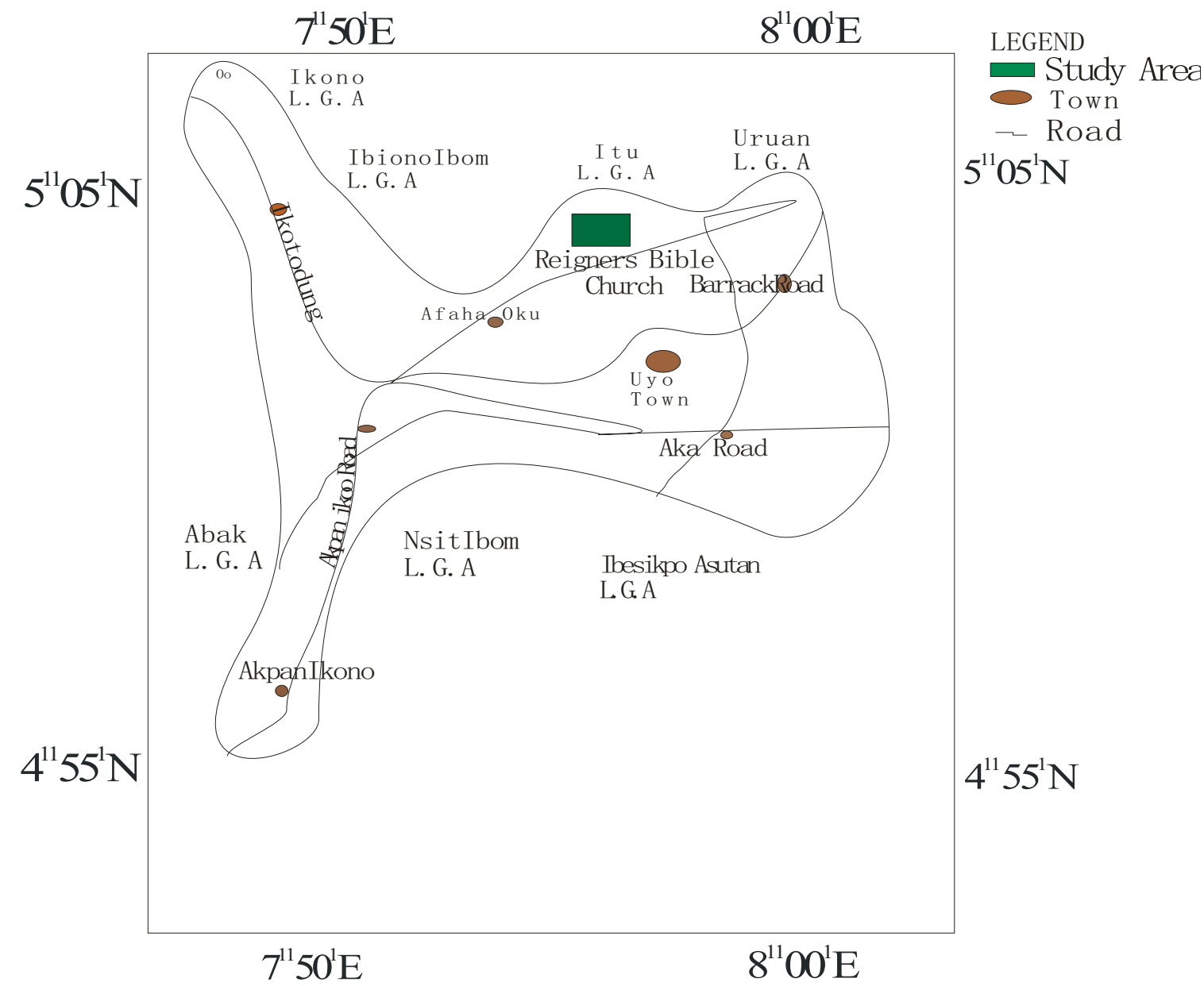

Fig. 1: Map of uyo local government area showing the study area and its environment

\subsection{Theory}

When seismic refraction source is shot the seismic signal is generated, a series of geophone laid receive the signal in a straight line along the surface, recorded on the seismograph and displaced on the screen. The refracted arrival 
times $(\mathrm{t})$ of $\mathrm{P}$ and $\mathrm{S}$ waves are measured as a function of the distance (x) from the seismic source point, the seismic velocity $\left(V_{p}\right)$ of the Primary wave and $\left(V_{s}\right)$ of the Secondary wave of the underlying soil or rock are calculated as the reciprocal of the slope by plotting the first arrival time at each geophone against the distance from the seismic source. (Osazuwa et al, 2008).

The reciprocal of the slope of $V_{1}$ gives the velocity of the first layer while the slope of $V_{2}$ gives the velocity of the second layer. Some of the soil properties could also be obtained by this method which includes: elastic properties; Young modulus, shear modulus, Lames constants and Poisson's ratio. Bearing capacity: allowable and ultimate bearing capacity and engineering properties: material index, concentration index, density gradient and stress. (Mohammed et al, 2013b)

\subsubsection{Shear Modulus}

Shear Modulus $(\mu)$ measures the coefficient of elasticity for a shearing force which is expressed as shown in "Eqn. 1".

\subsubsection{Young modulus}

$$
\mu=\frac{E}{2(1+\sigma)}
$$

Young modulus (E) measures the stiffness of solid materials deformation as shown in "Eqn. 2".

$$
\mathrm{E}=\rho\left[\frac{3 V_{P}^{2}-4 V_{S}^{2}}{\left(\frac{V_{S}}{V_{P}}\right)^{2}-1}\right]
$$

$P$ is the density of the sample layers.

\subsubsection{Poisson ratio}

Poisson ratio $(\sigma)$ measures the Poisson effect of a material as shown in "Eqn. 3".

$$
\sigma=\frac{1}{2}\left[1-\frac{1}{\left(\frac{V_{S}}{V_{P}}\right)^{2}-1}\right]
$$

\subsubsection{Lame's constant}

Lame's constant $(\lambda)$ measures the relationship of stress to strain of the elastic materials. It is expressed as shown in "Eqn.4".

$$
\lambda=\frac{\sigma E}{(1+\sigma)(1-\sigma)}
$$

1.2.5 Ultimate bearing capacity

Ultimate bearing capacity $\left(\mathrm{q}_{\mathrm{f}}\right)$ measures the intensity of bearing pressure at which the supporting ground is expected to fail in shear as shown in "Eqn. 5".

$$
\begin{gathered}
q_{f}=\frac{4 \gamma V_{S}}{40} \\
\gamma=\gamma_{0}+0.002 V_{p}
\end{gathered}
$$

$\gamma$ is the unit weight of the soil, $\gamma_{0}=16 \mathrm{KN} / \mathrm{m}^{3}$ which is the average unit weight of loose soil.

1.2.6 Allowable bearing capacity

Allowable bearing capacity $\left(\mathrm{q}_{\mathrm{a}}\right)$ measures the bearing pressure that will cause acceptance settlement of the structure against instability due to shear failures as expressed in "Eqn. 6".

$$
q_{a}=\frac{q_{f}}{n}
$$

Where $\mathrm{n}=4.0$ for soil, which is the factor of safety.

\subsubsection{Material Index}

Material Index $\left(V_{1}\right)$ measures the material property or a combination of material properties between a constraint and function of the material properties that leads to a particular performance index of material properties. It is expressed as shown in "Eqn. 8". 


$$
V_{1}=\frac{3-\left(V_{P} / V_{S}\right)^{2}}{\left(V_{P} / V_{S}\right)^{2}-1}
$$

\subsubsection{Stress Ratio}

Stress Ratio $\left(\mathbf{S}_{\mathbf{1}}\right)$ measures ultimate strength of the engineering material to the allowable stress. It also records the amount of deformation (strain) at distinct intervals of tensile or compressive loading (stress). It is expressed as shown in "Eqn. 9".

\subsubsection{Concentration Index}

$$
S_{1}=1-2\left(V_{S} / V_{P}\right)^{2}
$$

Concentration Index $\left(\mathbf{C}_{\mathbf{1}}\right)$ measures the concentration of the load and soil strength which describe the magnitude of the shear stress that a soil can sustain as a result of friction and interlocking of the soil. It is expressed as shown in "Eqn.10".

$$
C_{1}=\frac{3-4\left(\frac{V_{S}^{2}}{V_{P}^{2}}\right)}{1-2\left(\frac{V_{S}^{2}}{V_{P}^{2}}\right)}
$$

\subsubsection{Density Gradient}

Density Gradient $\left(\mathbf{D}_{\mathbf{1}}\right)$ measures the spatial variation in the density of engineering material which varies with temperature and pressure. It is expressed as shown in "Eqn. 11".

$$
D_{1}=\left[\left(\frac{3}{V_{P}^{2}}\right)-\left(\frac{4 \mu}{\mathrm{E}}-1\right)\right]
$$

\subsection{METHODOLOGY}

Five seismic refraction profiles were surveyed in order to obtain adequate data for this study. Each profile length extended between 5 and $60 \mathrm{~m}$, inter-geophone spacing of $5 \mathrm{~m}$ was used and the shot-to-first geophone spacing was also $5 \mathrm{~m}$ as shown in "Figs. 2 and 3". A total number of 12 P-waves and 12 S-waves geophones were used for forward and reverse shooting on every $60 \mathrm{~m}$ profiles length. To generate $\mathrm{P}$ waves, 2 shots were recorded at each location with 2 stacks per shot location. In $\mathrm{S}$ waves, 4 shots were recorded at each location with 2 stacks per shot location. A 12 channels ES 30000 s Seismogram was used for the data acquisition and energy source engaged was a $12 \mathrm{~kg}$ sledgehammer used to generate $\mathrm{P}$ and $\mathrm{S}$ waves as shown in "Figs. 10 to 12". Other equipment used was; metal plate 4 by $6 \mathrm{~cm}$, electrical cables and $48 \mathrm{H}_{z}$ frequency geophones respectively. This was done in order to adequately cover the refractor layer in the subsurface and to improve the quality of the image. High consideration was given to possible sources of noise such as machinery, human activities and other similar factors so as to improve the signal-to-noise ratio. The density values for the two layers were obtained in the laboratory of collected samples from outcrops. From this seismic refraction method, the refracted arrival times of the recorded signal were picked using SeisImager software packages of Pickwin and IX-Refrax and plotted as T$\mathrm{X}$ graph showing two velocity layers $\left(V_{1}\right.$ and $\left.V_{2}\right)$. The reciprocal of the slope of $V_{1}$ gives the velocity of the first layer while the slope of $V_{2}$ gives the velocity of the second layer. This value of the two velocities was used to determine other related parameters and state of stress of the soil for the two layers using theories of "Eqns. 1 to 11" and "Figs. 8 to 9 and 13" respectively. (ABEM, 1996)

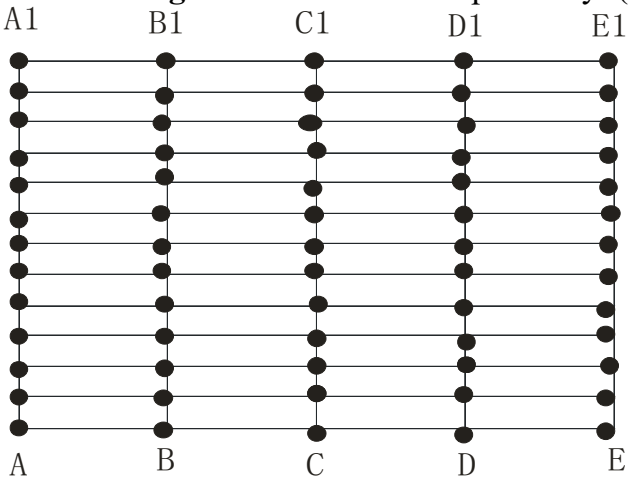

Fig. 2: Five seismic refraction survey layout

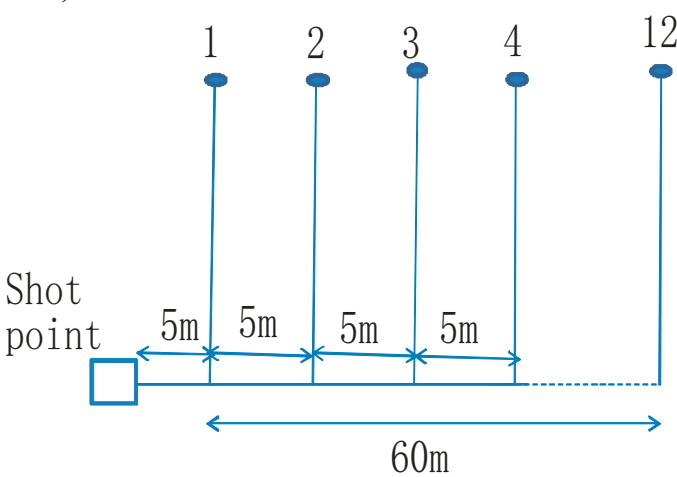

Fig. 3: Geophones field setup 


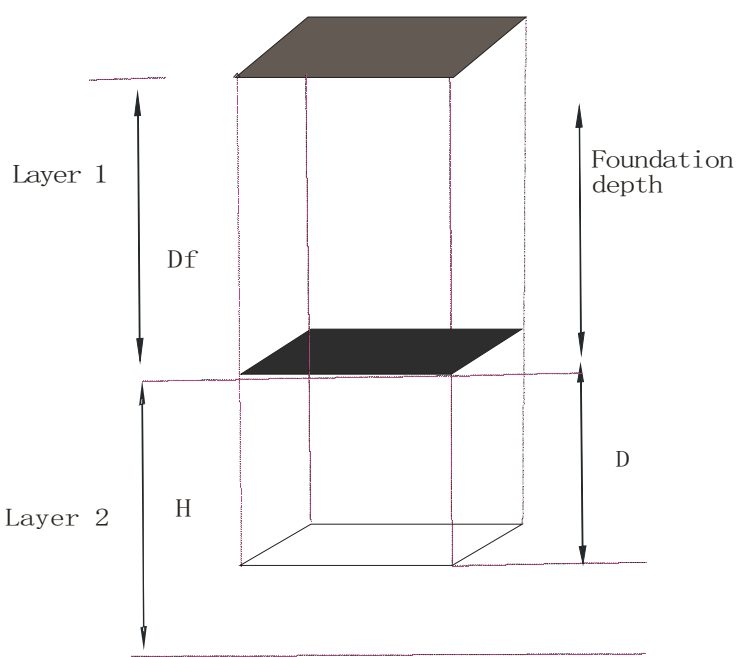

Fig. 4: Soil column and related parameters

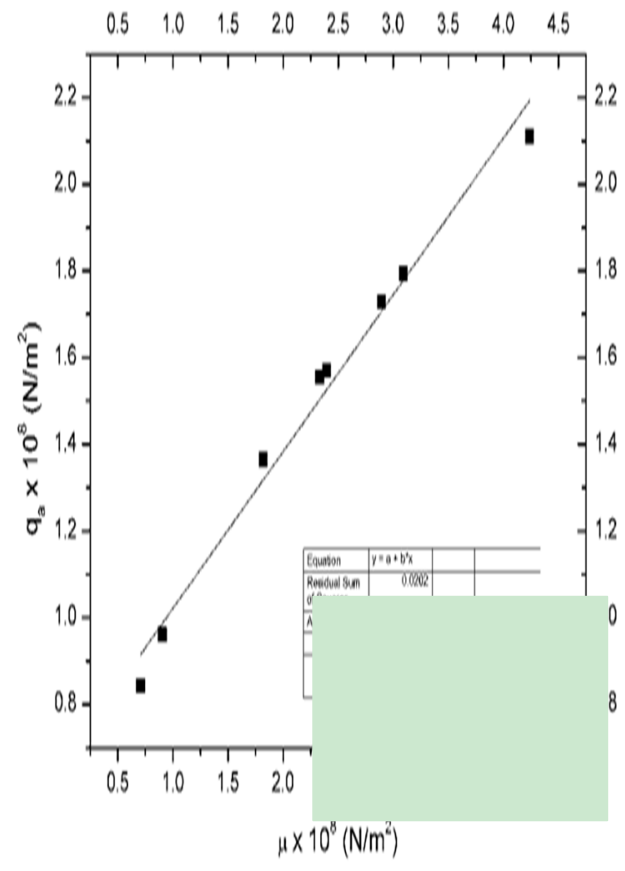

Fig. 8: A plot of $q_{a} \times 10^{8}\left(\mathrm{~N} / \mathrm{m}^{2}\right)$ against $\mu \times 10^{8}\left(\mathrm{~N} / \mathrm{m}^{2}\right)$ for layer 1

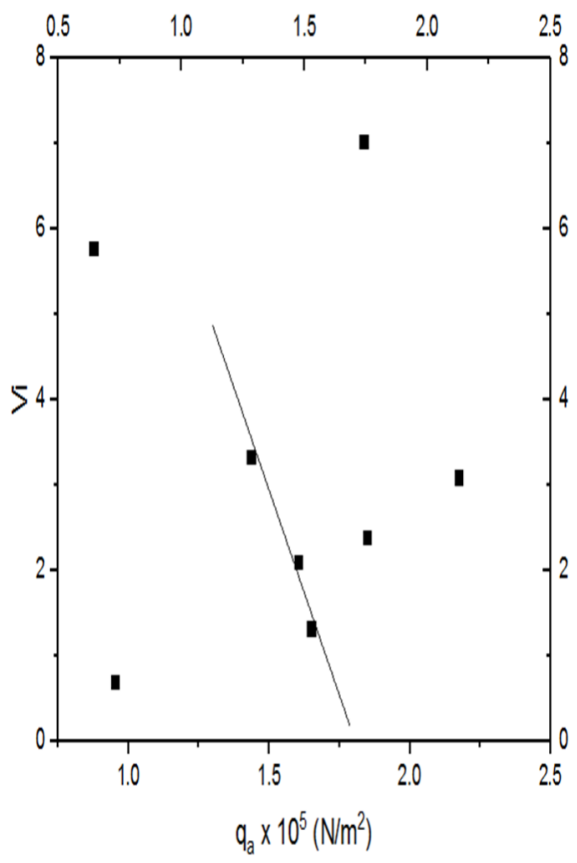

Fig. 9: A plot of $V_{I}$ against $q_{a} \mathrm{x}$ $10^{8}\left(\mathrm{~N} / \mathrm{m}^{2}\right)$ for layer 2 


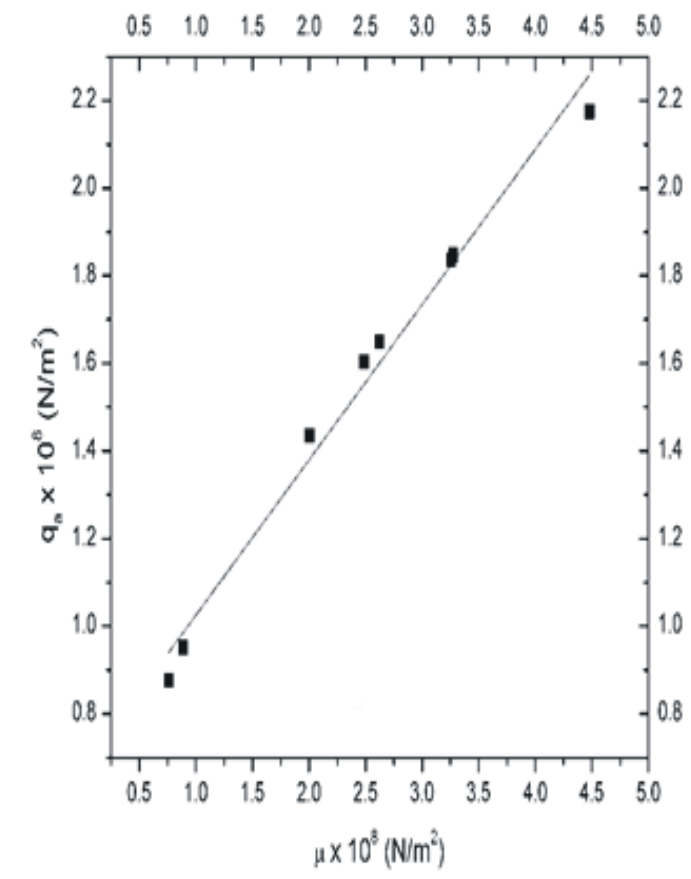

Fig. 13: A plot of $q_{a} \times 10^{8}\left(\mathrm{~N} / \mathrm{m}^{2}\right)$ against $\mu \times 10^{8}\left(\mathrm{~N} / \mathrm{m}^{2}\right)$ for layer 2

Table 1: Summary of measured and elastic parameters

\begin{tabular}{|l|l|l|l|l|l|l|l|l|}
\hline $\begin{array}{l}\text { Location } \\
\mathrm{S}\end{array}$ & $\begin{array}{l}\text { Layer } \\
\mathrm{s}\end{array}$ & $\begin{array}{l}\mathrm{V}_{\mathrm{P}}(\mathrm{m} / \mathrm{s} \\
)\end{array}$ & $\begin{array}{l}\mathrm{V}_{\mathrm{S}}(\mathrm{m} / \mathrm{s} \\
)\end{array}$ & $\Sigma$ & $\begin{array}{l}\mathrm{E}\left(\mathrm{KN} / \mathrm{m}^{2}\right. \\
)\end{array}$ & $\begin{array}{l}\lambda \\
\left(\mathrm{KN} / \mathrm{m}^{2}\right. \\
)\end{array}$ & $\begin{array}{l}\gamma\left(\mathrm{KN} / \mathrm{m}^{3}\right. \\
)\end{array}$ & $\begin{array}{l}\mu\left(\mathrm{KN} / \mathrm{m}^{2}\right. \\
)\end{array}$ \\
\hline $\mathrm{A}$ & 1 & 550.5 & 420.2 & 1.698 & -670.8 & 604.8 & 17.10 & -904.9 \\
& 2 & 790.2 & 510.0 & 1.357 & -249.8 & 402.8 & 17.58 & -294.4 \\
\hline $\mathrm{B}$ & 1 & 600.2 & 489.5 & 1.9932 .60 & -503.9 & 337.9 & 17.20 & -754.2 \\
& 2 & 825.5 & 720.6 & 1 & 240.5 & 108.5 & 17.65 & 433.0 \\
\hline $\mathrm{C}$ & 1 & 500.4 & 400.0 & 1.885 & -425.1 & 313.8 & 17.01 & $-61.3 \mathrm{I}$ \\
& 2 & 720.0 & 590.5 & 2.027 & -857.6 & 559.0 & 17.44 & -129.8 \\
\hline $\mathrm{D}$ & 1 & 852.5 & 600.5 & 1.492 & -202.1 & 245.8 & 17.71 & -251.8 \\
& 2 & 1000.2 & 825.0 & 2.064 & -15.25 & 965.8 & 18.01 & -233.8 \\
\hline $\mathrm{E}$ & 1 & 901.2 & 720.5 & 1.886 & -137.7 & 101.6 & 17.80 & -137.7 \\
& 2 & 1010.3 & 901.2 & 2.947 & 159.8 & 612.6 & 18.02 & 315.3 \\
\hline
\end{tabular}

Table 2: Summary of bearing and engineering parameters

\begin{tabular}{|l|l|l|l|l|l|}
\hline $\mathrm{q}_{\mathrm{a}}\left(\mathrm{N} / \mathrm{m}^{2}\right)$ & $\mathrm{q}_{\mathrm{f}}\left(\mathrm{N} / \mathrm{m}^{2}\right)$ & $\mathrm{V}_{1}$ & $\mathrm{C}_{1}$ & $\mathrm{D}_{1}$ & $\mathrm{~S}_{1}$ \\
\hline 17.96 & 718.5 & 1.792 & -4.051 & -4.396 & -0.165 \\
25.5 & 10.20 & 0.428 & 7.992 & -3.714 & -3.894 \\
\hline 21.05 & 842.0 & 2.973 & -1.03 & -4.986 & -0.330 \\
36.03 & 144.1 & 4.403 & 0.092 & -6.202 & -1.625 \\
\hline 17.01 & 680.03 & 2.540 & -1.598 & -4.770 & -0.278 \\
29.53 & 118.21 & 3.109 & -0.896 & -5.055 & -1.973 \\
\hline 26.58 & 106.31 & 0.992 & 1.328 & -3.985 & 0.007 \\
41.25 & 165.00 & 3.257 & -0.77 & -5.129 & -1.940 \\
\hline 32.07 & 128.27 & 2.543 & -1.592 & -4.772 & -0.278 \\
45.06 & 180.24 & 6.789 & 0.309 & -6.894 & -1.514 \\
\hline
\end{tabular}

\subsection{Result and Discussion}

The refracted travel times of all recorded traces were picked and analyzed using seisImager packages of pickwin and IXrefract software. The seismic tomography section revealed two geologic layers in the study area. That is, 
layers 1 and 2. The P-wave velocity of the first layer ranged from 500.4 to $901.2 \mathrm{~m} / \mathrm{s}$ while in the second layer, the velocity was between 720 and $1010.3 \mathrm{~m} / \mathrm{s}$. The S-wave velocity of the first layer ranged from 400.0 and 720.5 $\mathrm{m} / \mathrm{s}, 510.0$ and $901.2 \mathrm{~m} / \mathrm{s}$ in the second layer respectively. Other parameters were determined as shown in "Table 1". In layer 1: Poisson ratio ranged from 1.49 to 1.99, Young's modulus ranged from between -425.1 to -2021.1 $\mathrm{KN} / \mathrm{m}^{2}$, Lames constant ranged from 245.8 to $313.8 \mathrm{KN} / \mathrm{m}^{2}$, Shear modulus ranged from -613.1 to $-2518.7 \mathrm{KN} / \mathrm{m}^{2}$, Ultimate capacity ranged from 680.0 to $1282.7 \mathrm{~N} / \mathrm{m}^{2}$, Allowable capacity ranged from 170.0 to $320.7 \mathrm{~N} / \mathrm{m}^{2}$, Material index ranged from 0.97 to 2.97, Concentration index -1.03 to 132.8, Density gradient ranged from -3.98 to -4.99 and Stress ratio ranged from 0.007 to -0.16 . In layer 2: Poisson ratio ranged from 1.36 to 2.94, Young's modulus ranged from between 240.5 to $1597.7 \mathrm{KN} / \mathrm{m}^{2}$, Lames constant ranged from -108.5 to $965.8 \mathrm{KN} / \mathrm{m}^{2}$, Shear modulus ranged from 432.9 to $3153.1 \mathrm{KN} / \mathrm{m}^{2}$, Ultimate capacity ranged from 102 to $180.24 \mathrm{~N} / \mathrm{m}^{2}$, Allowable capacity ranged from 255.0 to $450.6 \mathrm{~N} / \mathrm{m}^{2}$, Material index ranged from 0.43 to 6.97 , Concentration index 0.09 to 7.99 , Density gradient ranged from -3.71 to -6.89 and Stress ratio ranged from -1.51 to -3.80 as shown in "Table 2" respectively. The depths and thickness ranged from 0.0 to 5.0 and $5.0 \mathrm{~m}$ for the topsoil while the second layer ranged from 5.5 to 13.0 and $7.5 \mathrm{~m}$. Geotechnically, the geologic formation with higher values of parameters are considered for engineering construction purposes as observed in the second layer.

The result revealed that the first layer is composed of unconsolidated formation of soft geomaterials and peaty clay that depict the lower values of parameters. This layer is underlain directly by clay, wet sand and sandy clay of soft and weak incompetent consistencies to a depth of $7 \mathrm{~m}$ in the subsurface. The second layer was found to have higher parameters than the first layer. The second layer revealed that the geologic formation composed of dry sand and sandy clay of fair to good competent. The geologic formation in the second layer was found to be more competent than the first layer with high allowable capacity and low ultimate failure potential. Geologically, the composition of the first layer is more recent in age of deposition than the second layer, characterized by unconsolidated geologic formation. The weak and incompetent geologic formation observed in the first layer shows that, there was no direct pressure of the geologic formation on top of the first layer that festinate the consolidation of the soil deposit. However, the second layer was found to be composed of fair to good consolidated geological formation than the first layer, based on the age of deposition which compressed by the presence of other recent deposit lying on it. The pressure exerted on the second layer by other geological formation lying on it helped to improve its engineering stability. Moreover, the depth to the most competent geologic formation was found in the second layer to be ranged from 5.5 to $13.0 \mathrm{~m}$ with the thickness of $7.5 \mathrm{~m}$ corresponding to consolidated layer in the subsurface.

The velocity of $\mathrm{S}$ waves increase with decrease in travel times due to the formation and absorption of fluid and gas in pore. Decrease in velocity of $\mathrm{P}$ waves increase with respect to increase in travel times due to decrease in shear modulus and rock density. The allowable bearing capacity was plotted with shear modulus which shows a linear relationship between the parameters as shown in "Figs. 9 and 8". The slope of the plots in "Fig. 8" shows dimensionless constants which give the coefficients of elastic deformation of the near surface cause by load imposed on the near surface. "Figs. 10 to 15" show the model distribution of elastic parameters, allowable and engineering parameters for layers 1 and 2 .

The 2-D model in "Figs. 10 and 11" shows a continuous increment in the shear modulus in the east - west trend in layer 1 and north - west in layer 2 and decrease in the east trend. "Figs. 12 to 15" show an increase of allowable bearing capacity and material index in the east trend and decrease in the west trend in layers 1 and 2. This trend shows that low allowable and elastic parameters is associated with zone that area highly drained with water while high bearing and elastic parameters are unsaturated with water. However, in 3-D model as shown in "Fig. 16", the location of high values of allowable and material index in the layer 1 conforms to the location noticed in layer 2 . These results demonstrate uniform consolidation trends from low to high value with depth in layer 1 and 2. This conformity reveals the uniqueness of the method used in investigating the near surface structures. On the other hand, this study revealed that any study area having similar geology formation, the second layer portion of the subsurface should be considered for engineering construction that will provide safety and stand the test of time. 
$\lambda(\mathbf{K N} / \mathrm{m} 2)$

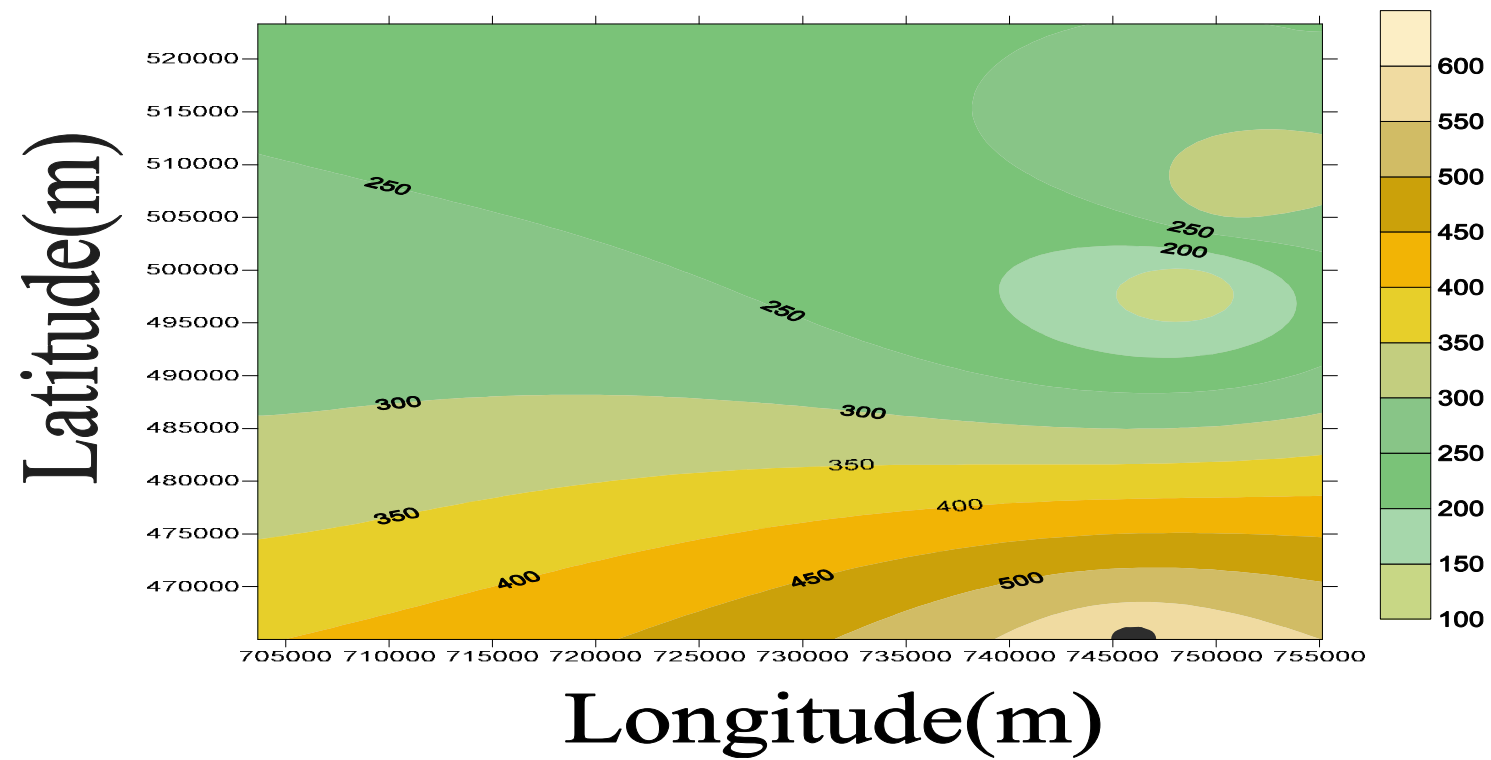

Fig. 10: 2-D contour map showing the distribution of $\lambda\left(\mathrm{KN} / \mathrm{m}^{2}\right)$ in layer 1 $\lambda(\mathrm{KN} / \mathrm{m} 2)$

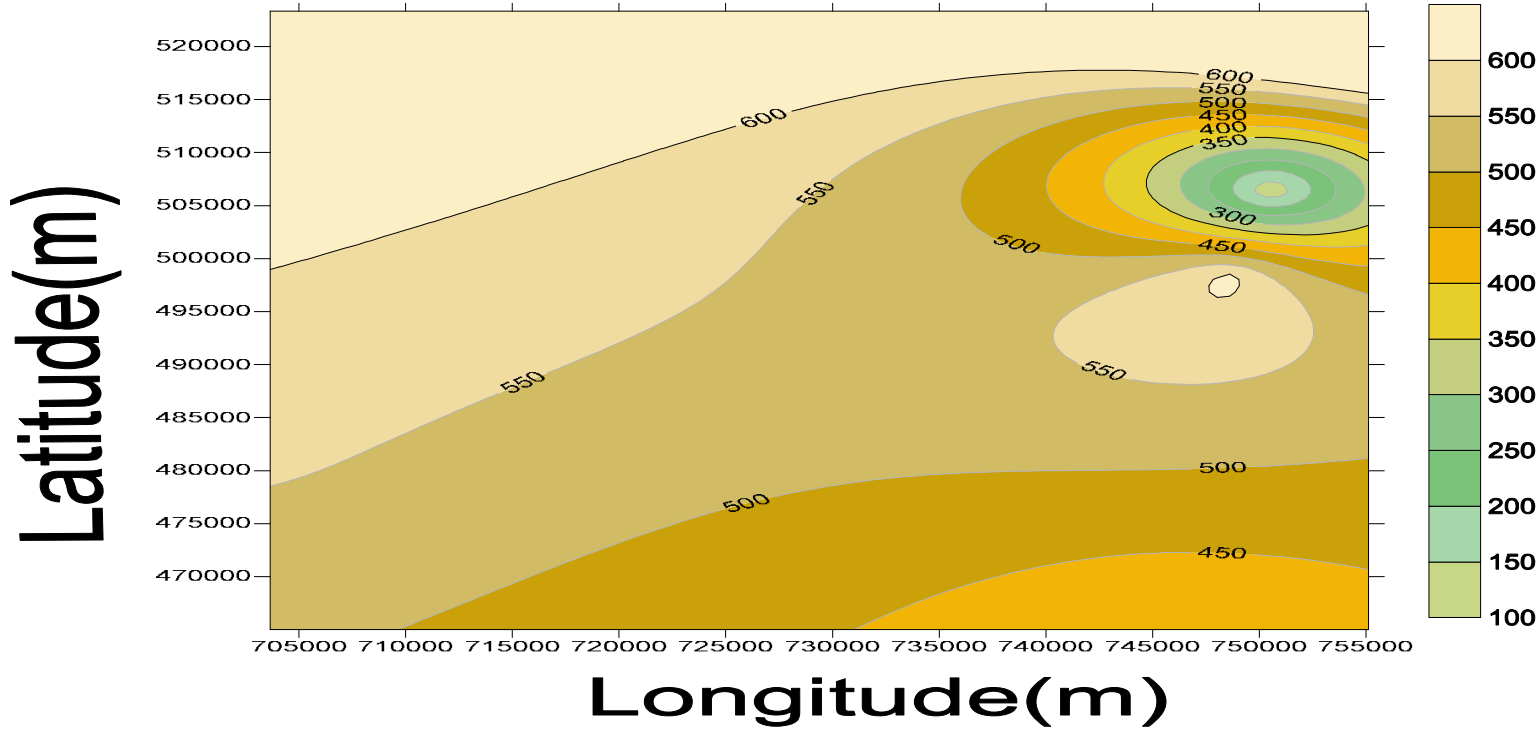

Fig. 11: 2-D contour map showing the distribution of $\lambda\left(\mathrm{KN} / \mathrm{m}^{2}\right)$ in layer 2 
qa $(N / m 2)$

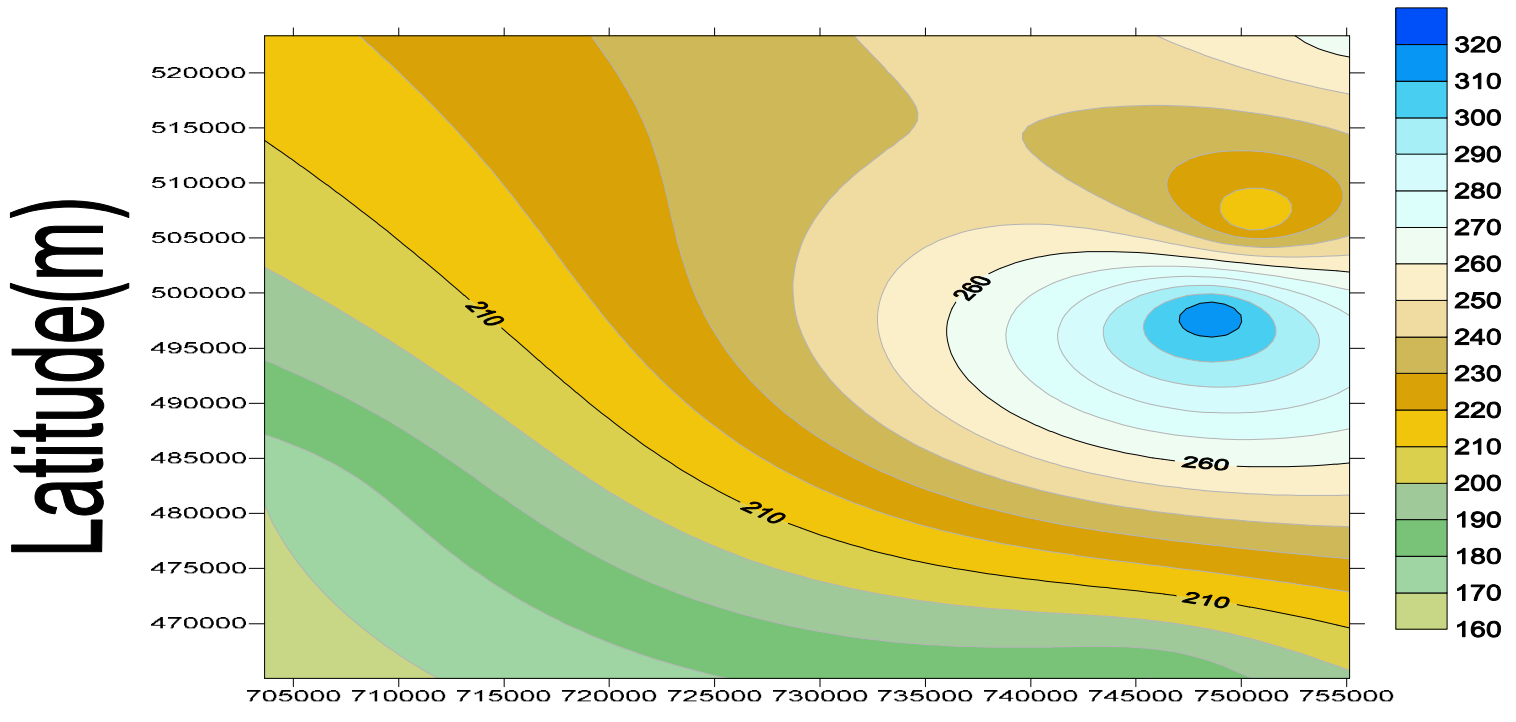

\section{Longitude $(\mathrm{m})$}

Fig. 12: 2-D contour map showing the distribution of $\mathrm{q}_{\mathrm{a}}\left(\mathrm{N} / \mathrm{m}^{2}\right)$ in layer 1

qa $(\mathrm{N} / \mathrm{m} 2)$

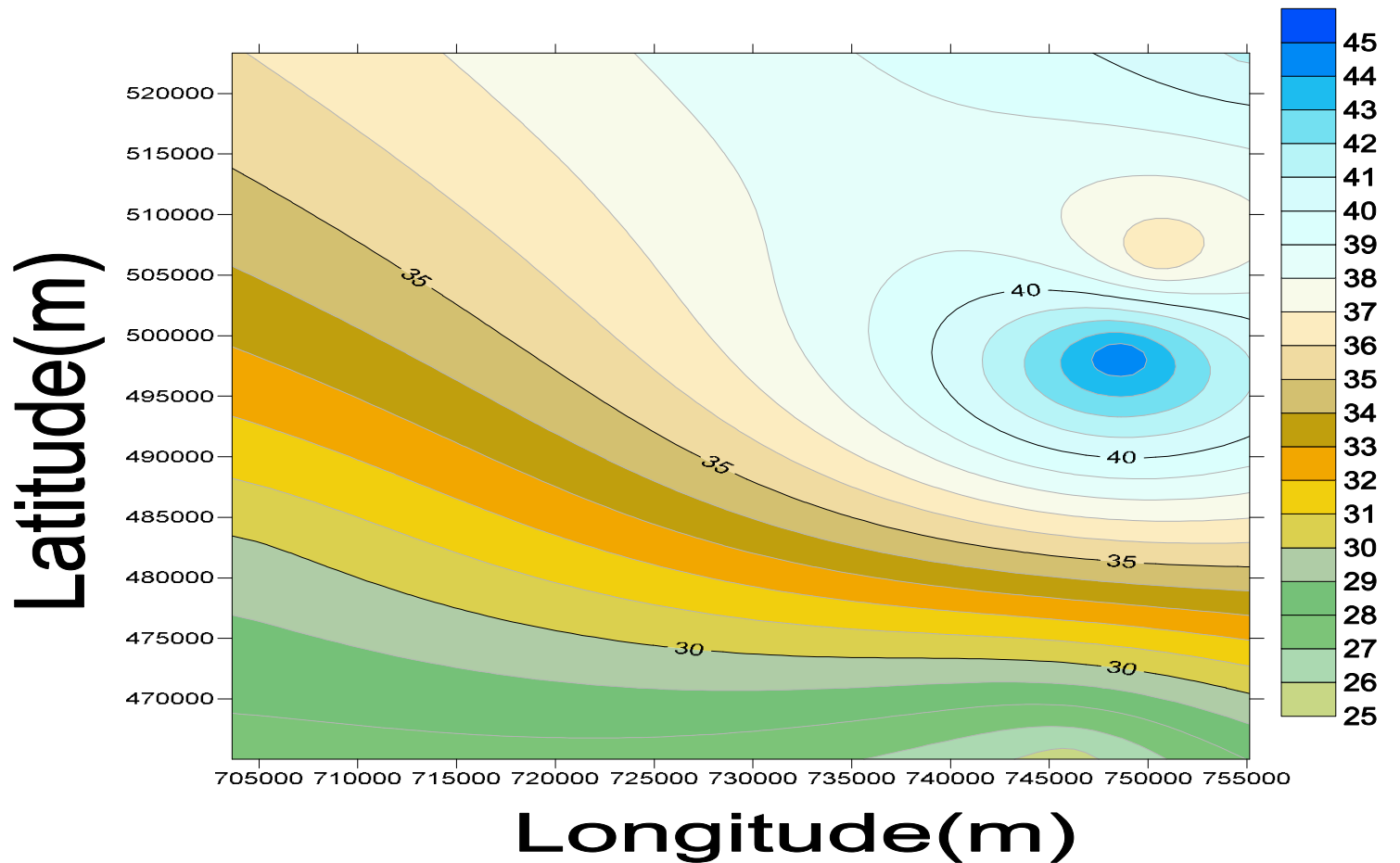

Fig. 13: 2-D contour map showing the distribution of $\mathrm{q}_{\mathrm{a}}\left(\mathrm{N} / \mathrm{m}^{2}\right)$ in layer 2 


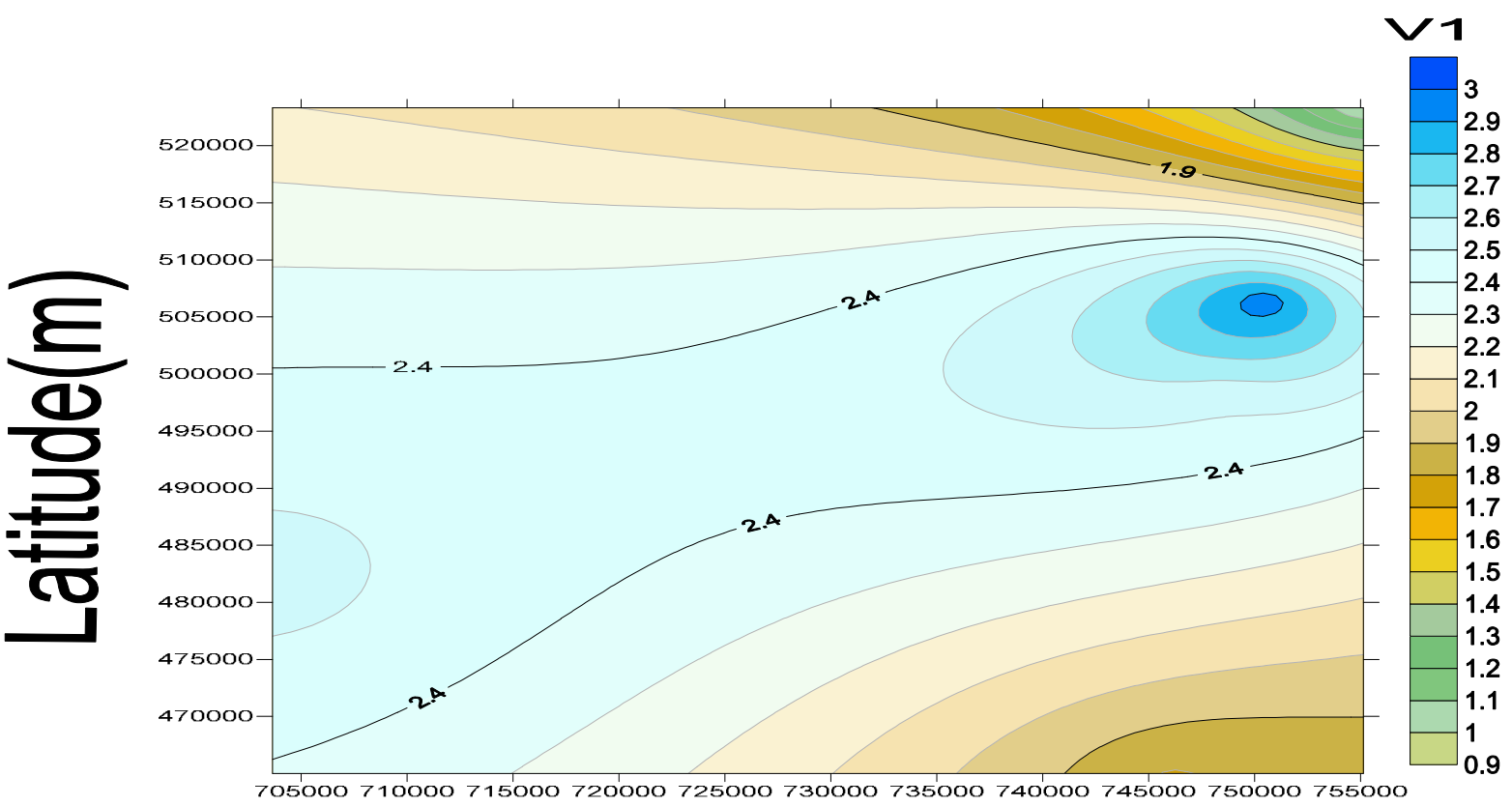

\section{Longitude $(m)$}

Fig. 14: 2-D contour map showing the distribution of $V_{1}$ in layer 1

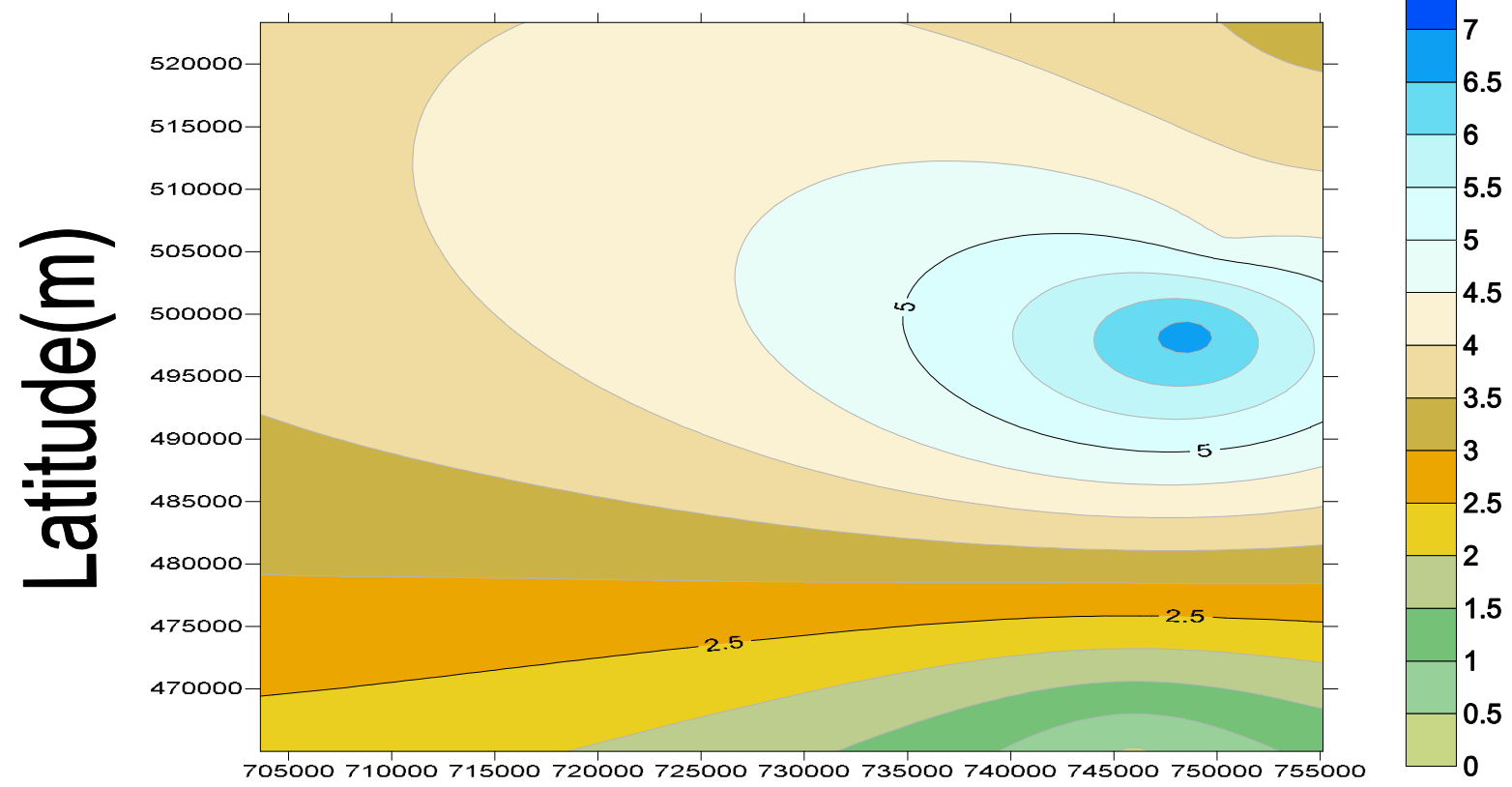

\section{Longitude $(\mathrm{m})$}

Fig. 15: 2-D contour map showing the distribution of $V_{1}$ in layer 2 


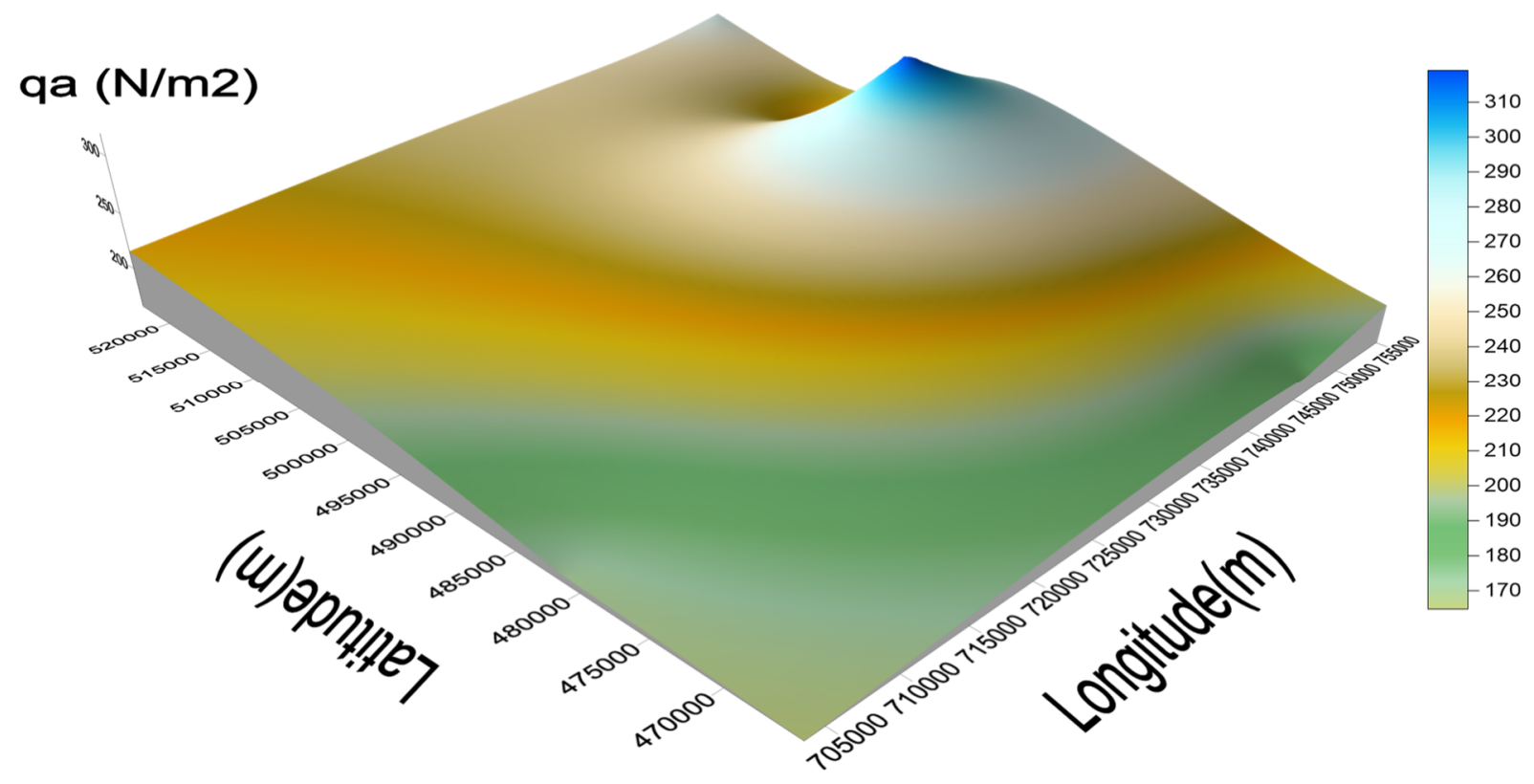

Fig. 16: 3-D model showing the distribution of $\mathrm{qa}\left(\mathrm{N} / \mathrm{m}^{2}\right)$ in layer 1

\section{References}

ABEM Instrument AB 1996 Equipment Manual for TERRALOC MK6 Software Version 2.21 Bromma Sweden.

Aka, M.U; Umoh, J.A (2013): Determination of weathering thickness and velocity of the near surface layer using uphole seismic refraction. J. Earth Sci. Geotech. Eng. 1(1):77-86

George. N.J; Akpan, George, A.E; Obot, I.B: Resistivity Study of Shallow Aquifer in parts of Southern Ukanafun Local Government Area; Akwa Ibom State: E-J Chem., 7(3) (2010)- pp 693-700.

Dobrin M.B. (1976). Introduction to geophysical prospecting, Mc Graw-Hill Book C.O, New York.

Fatoba, J.O; Alo, J.O and Fakeye, A.A (2010): Geoelectric Imaging for foundation failure investigation at Olabisi Onabanjo University mini campus, Ago Iwoye, South-western Nigeria. Journal of Applied Sciences Research $6(12), 2192-2198$.

Harry, T.A, Etuk, S. E, Joseph, Okoli Austin (2018) Geomechanical evaluation of reservoirs in the coastal swamp, Niger delta region of Nigeria. 2018, 2018. 6(2): p. 8

Harry, T.A, Ushie, F.A, Agbasi, O. E (2018): Hydraulic and Geoelectric relationships of Aquifers Using Vertical Electrical Sounding (VES) in parts of Obudu, Southern Nigeria. Vol. 94.

Mohamed A M E, Abu El Ata A S A, Azim F A and Taha M A (2013b): Site-specific shear wave velocity investigation for geotechnical engineering applications using seismic refraction and $2 \mathrm{D}$ multi-channel analysis of surface waves National Research Institute of Astronomy and Geophysics 288

Oyedele KF, Oladele S, Adedoyin O (2011). Application of Geophysical and Geotechnical Methods to Site Characterization for Construction Purposes at Ikoyi, Lagos, Nigeria. J. Earth Sci. Geotech. Eng. 1(1):87-100.

Osazuwa I B and Chinedu A D 2008 Seismic refraction tomography imaging of highpermeability zones beneath an earthen dam, in Zaria area Nigeria Journal of Applied Geophysics 6644

Zhang, J.; Toksoz, M.N; 1998: Non-linear Refraction Travel time Tomography, Geophysics, 63(5): 1726-1737 CrossRef google. Scholar, Zhu; X. 